\title{
Changes in the Building Stock of Da Nang between 2015 and 2017
}

\author{
Andreas Braun ${ }^{1, *} \mathbb{( D}$, Gebhard Warth ${ }^{1}$, Felix Bachofer ${ }^{2}\left(\mathbb{D}\right.$, Tram Thi Quynh Bui ${ }^{3}$, Hao Tran ${ }^{4}(\mathbb{D}$ \\ and Volker Hochschild ${ }^{1}$ \\ 1 Institute of Geography, University of Tübingen, 72070 Tübingen, Germany; \\ gebhard.warth@uni-tuebingen.de (G.W.); volker.hochschild@uni-tuebingen.de (V.H.) \\ 2 German Aerospace Center (DLR), Earth Observation Center (EOC), 82334 Wessling, Germany; \\ felix.bachofer@dlr.de \\ 3 Da Nang Institute for Socio-Economic Development (DISED), Da Nang City 550000, Vietnam; \\ trambtq6688@gmail.com \\ 4 Da Nang Urban Planning Institute (UPI), Da Nang City 550000, Vietnam; tranhaoupi@gmail.com \\ * Correspondence: an.braun@uni-tuebingen.de; Tel.: +49-7071-297-8940
}

Received: 16 March 2020; Accepted: 20 April 2020; Published: 23 April 2020

check for updates

\begin{abstract}
This descriptor introduces a novel dataset, which contains the number and types of buildings in the city of Da Nang in Central Vietnam. The buildings were classified into nine distinct types and initially extracted from a satellite image of the year 2015. Secondly, changes were identified based on a visual interpretation of an image of the year 2017, so that new buildings, demolished buildings and building upgrades can be quantitatively analyzed. The data was aggregated by administrative wards and a hexagonal grid with a diameter of $250 \mathrm{~m}$ to protect personal rights and to avoid the misuse of a single building's information. The dataset shows an increase of 19,391 buildings between October 2015 and August 2017, with a variety of interesting spatial patterns. The center of the city is mostly dominated by building changes and upgrades, while most of the new buildings were constructed within a distance of five to six kilometers from the city center.
\end{abstract}

Dataset: https://doi.org/10.5281/zenodo.3757710

Dataset License: CC-BY 4.0

Keywords: building types; change detection; remote sensing; urbanization; urban growth; Southeast Asia

\section{Summary}

Rapidly urbanizing cities require reliable and up-to-date information about their inhabitants to ensure the provision of food and energy, but also for the planning of logistics, public services and infrastructure. However, the collection of this information by surveys or an official census is time-consuming and expensive. As an alternative, methods of earth observation can be employed to extract the number of buildings as an indicator of the size and spatial distribution of the urban population [1,2]. The presented dataset provides building types and numbers for the city of Da Nang for the years 2015 and 2017. The initial number of building types was retrieved from a very high-resolution (VHR) Pléiades satellite image using an object-based image analysis (OBIA) approach, as was already described in two previous studies by the authors [3,4]. Results from these studies were then refined by the approach presented in this data descriptor to extract the changes between 2015 and 2017 based on visual inspection and the identification of changes, classified into five different categories: no change, new building, changed building, upgraded building and demolished building. 
The building types and changes were aggregated in two datasets: administrative boundaries and hexagons of $250 \mathrm{~m}$ in width. These two datasets are the first publicly available and most up to date assessments of the building stock of Da Nang. Such information is valuable for urban planners to estimate the future growth of the city, the demand of the population (food, energy, or water) and the persons potentially affected by rising sea levels under climate change.

\section{Methods}

Several steps were required to identify the changes in the urban area of Da Nang, including the collection of reference data, the retrieval of built-up areas and building types from satellite images and the visual identification of changes over the investigated period. These steps are summarized in Figure 1.

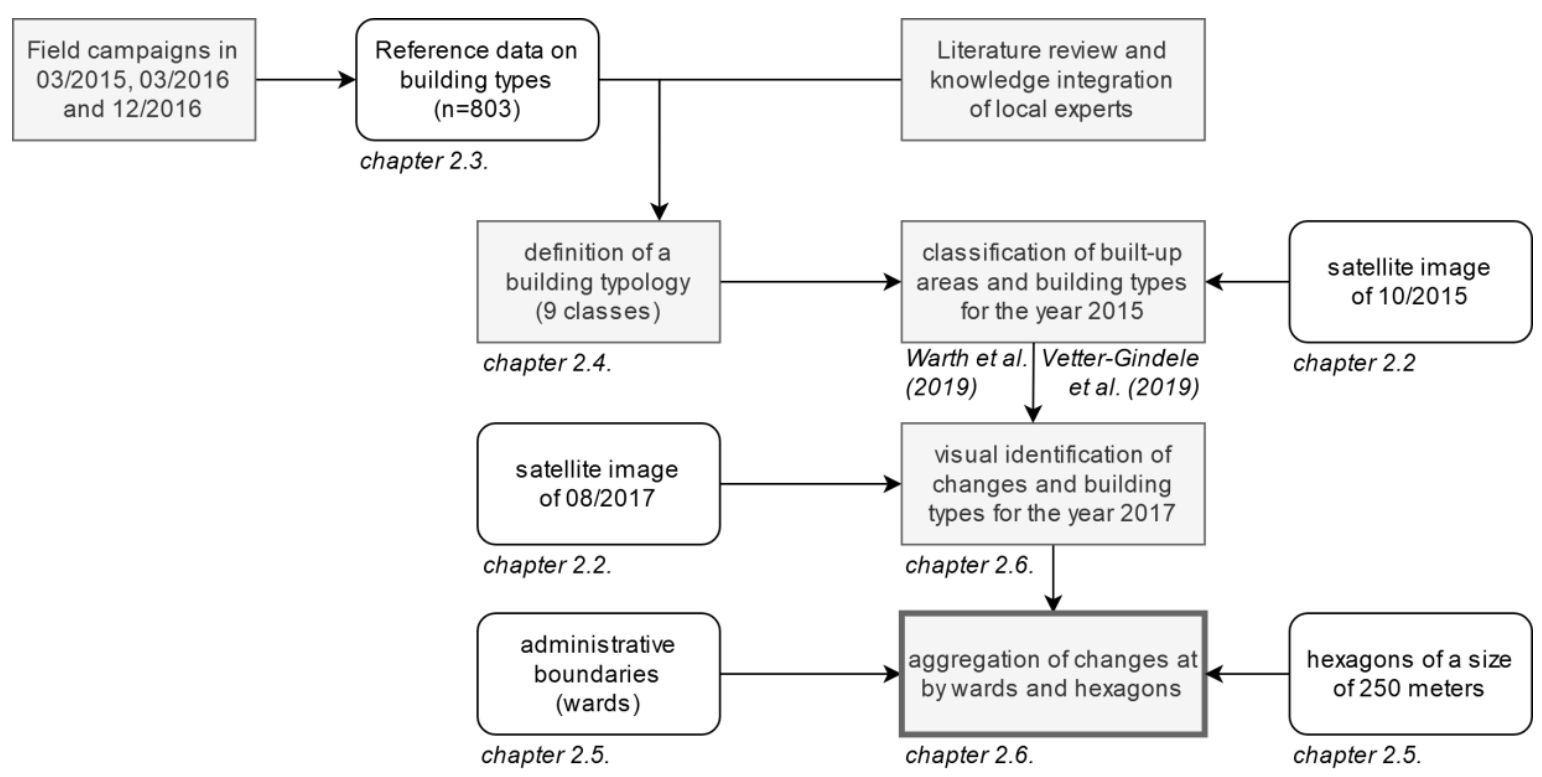

Figure 1. Systematic workflow for the creation of the presented dataset.

\subsection{Study Area}

The study area covers the urban and suburban parts of the city of Da Nang, located in Central Vietnam. It has a population of 1.125 million inhabitants, with an annual growth rate around $2.75 \%$ according to the estimates of the United Nations [5]. Because of its harbor, which is the fourth largest in the country, the entirety of Central Vietnam has become economically important and has experienced a considerable population increase since 2007, mostly due to migration from rural areas [6]. The administrative area covered by the dataset is divided into seven districts and 50 wards (Figure 2, black lines), of which six districts belong to the city of Da Nang. Because the acquisition of VHR data is limited by financial and technical constraints, an area of interest (AOI) of 225 square kilometers was defined for the analysis (Figure 2, red line), which covers the urban and suburban settlement areas of the city and large parts of its rural surroundings. Because of the seamless transition of the urban area at the southern border of the study area, parts of the Điện Bàn district of the adjacent Quảng Nam province are also covered by the AOI and thus have been included in the presented dataset. 


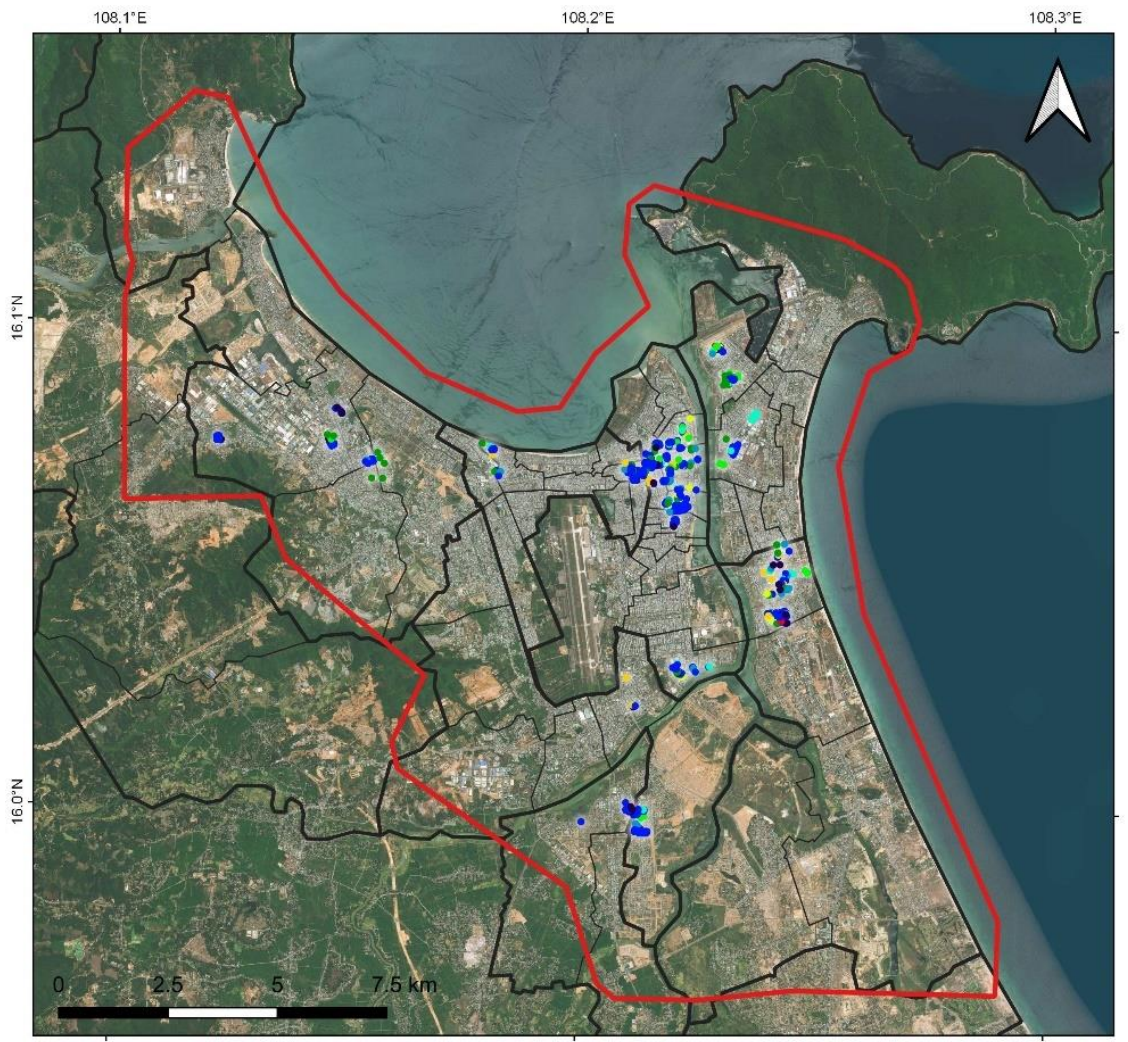

\author{
Legend \\ extents \\ $\square$ VHR satellite images \\ $\square$ administrative districts \\ $\square$ administrative wards \\ building reference data [803] \\ - single family, basic [65] \\ - local-type shophouse [540] \\ - single family, bungalow [29] \\ - single family, villa [39] \\ - multi-family, local [53] \\ - multi-family, modern [33] \\ - special [11] \\ - hall [16] \\ - outbuilding [5] \\ Reference data were collected between \\ $03 / 2015$ and $12 / 2016$ by researchers of \\ the Institute of Geography of the \\ University of Tübingen and the Institute of \\ Energy Economics and Rational Energy
Use (IER) of the University of Stuttgart \\ Map projection: UTM 48N (EPSG:32648) \\ Data sources: \\ Data sources:
Administrative boundaries: $\odot 2018$
GADM, version 3.6 \\ Satellite basemap: $\odot 2020$ Digital Globe
}

Figure 2. Study area, extent of the analysis, and field reference data collection.

\title{
2.2. Satellite Data
}

Two image products from the Pléiades satellite constellation acquired on 24.10.2015 and 13.08.2017 were used in this study. For this period, the United Nations estimated a growth of $3.5 \%$ for the city of Da Nang [5]. The sensor acquires four multispectral bands (blue, green, red, and infrared) at $2.8 \mathrm{~m}$ and one panchromatic band at $0.7 \mathrm{~m}$ spatial resolution (resampled to $50 \mathrm{~cm}$ by the data provider). Both products were pan-sharpened to a final spatial resolution of $50 \mathrm{~cm}$ and radiometrically and geometrically calibrated as described by Warth et al. [4]. The two images were acquired from slightly different off-nadir angles, which resulted in the geometric shift of high buildings towards the sensor. Furthermore, the different acquisition dates within the year lead to differences in illumination and the shadows that are cast from large objects. Lastly, there are phenologic differences between October and August, so urban greenspaces or trees can produce unequal patterns in both images. All these slight distortions can make the visual identification of changes challenging, especially in densely built-up areas.

Figure 3 gives an example on the differences between both images for a small selected area in the An Hải Bắc ward of the Sơn Trà district in the eastern part of Da Nang. Although the building in the center has not changed between both image acquisitions, the red color of the roof looks different because of sunlight illumination. Moreover, the shadows at the northern edges of tall buildings are only present in the image from October 2015. These seasonal differences were reduced during the radiometric calibration, but could not entirely be removed. Accordingly, these radiometric differences can potentially increase the chance of falsely assigned changes at the building level during the latter visual interpretation of changes at the building level. The figure also demonstrates that actual changes in the morphologic structure of the city, such as the creation of paved roads (in the northern and western part of the image), or the construction of new buildings (two bright lines in the center north) or other infrastructure (blue sports court in the center) can clearly be identified by visual comparison. 
However, slight differences had to be kept in mind by the interpreters in order to avoid errors of commission during the identification of changes between 2015 and 2017.
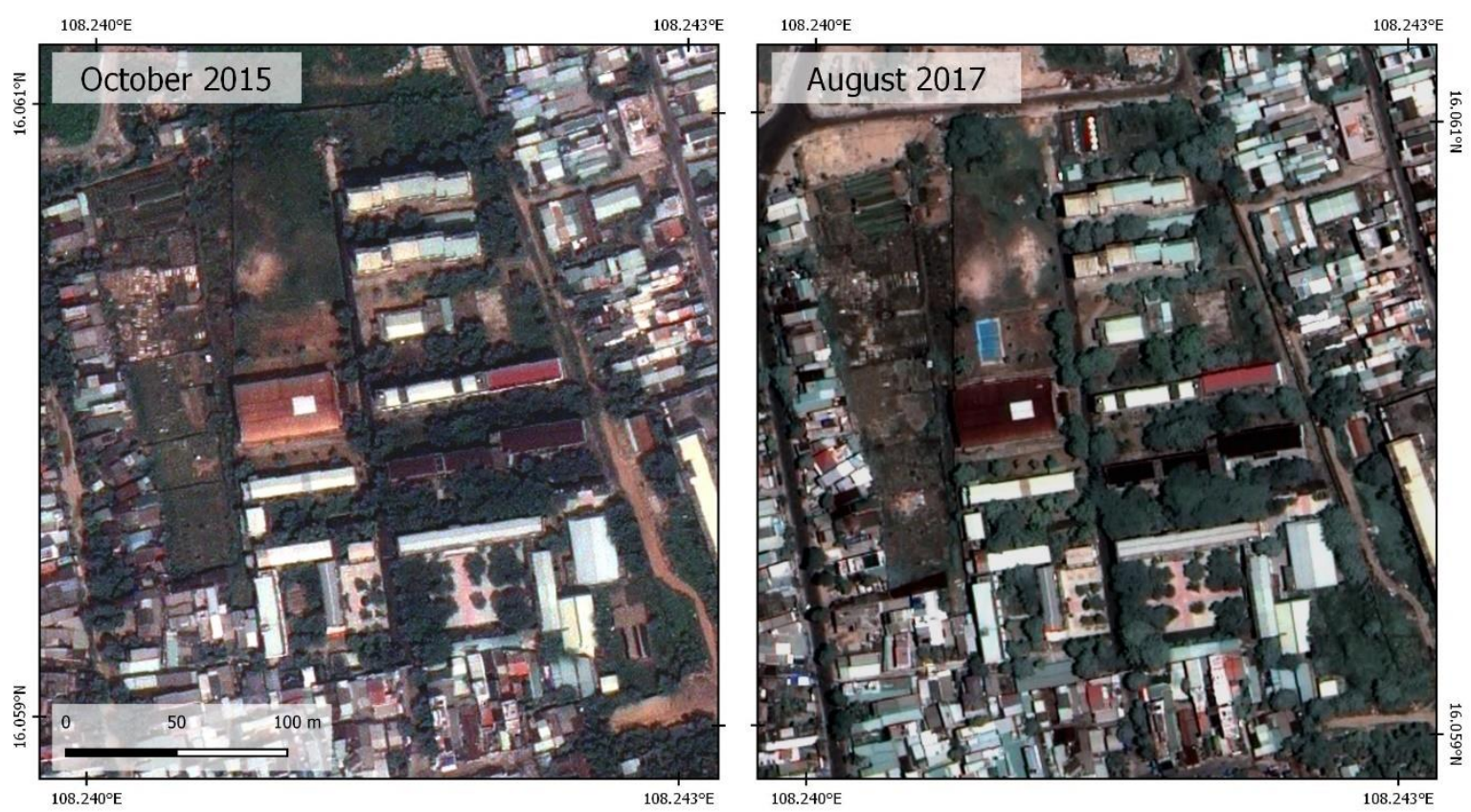

Figure 3. Radiometric differences resulting from angle and acquisition date/time of the two images used in this study.

As a qualitative historic reference, an image acquired on 15.08 .1977 by the Keyhole-9 (KH-9) mission "Hexagon" [7] was used in this study. Its spatial resolution of $7 \mathrm{~m}$ allowed us to identify the historic city center (see Section 3.2) of Da Nang.

\subsection{Reference Data}

To gain a better understanding of the city's morphology and the predominant building types, three field campaigns have been carried out in 2015 and 2016. Using mobile handheld tablet devices, a total number of 803 geocoded questionnaires on single buildings were collected, including information on building size, shape and height, its usage, the color and materials of the roof, photographs and further parameters regarding the structure of the buildings. These datasets were collected in March 2015 $(n=233)$, March $2016(n=465)$ and December $2016(n=105)$. Based on the collected data, building archetypes were defined in close collaboration with local experts. The spatial distribution of these buildings and the assigned building type are shown in Figure 1. Typically, in Vietnamese cities, shop houses with a longish shape and three to five floors of mixed use are the most common in the city. They can be refined into sub-classes (such as traditional, new, commercial, rowhouse), as initially suggested by Moon et al. (2009) [8], but only with additional knowledge about the degree of commercial use and construction materials, which cannot be retrieved from remote sensing data for the entire city.

\subsection{Building Typology}

The building typology was developed based on an existing study by Downes et al. (2016) for Ho Chi Minh City [9]. It has already been applied to estimate the number of different fractions of household waste [3] and was successfully transferred to the Rwandan capital, Kigali, to demonstrate the spatial patterns of urbanization between 2008 and 2015 [10]. The criteria for the building types are based on height, size, shape and roof material to allow an assignment of building types for the entire urban area of Da Nang, solely based on satellite image information. Table 1 lists the nine building types, together with a short description of their identification from remote sensing images. 
Table 1. Building archetypes for the City of Da Nang, adapted from Vetter Gindele et al. (2019) [3].

\begin{tabular}{|c|c|c|c|}
\hline ID & Building Type and Statistics & Description & Representative Reference Picture \\
\hline 1 & $\begin{array}{l}\text { Single family, basic }(n=65) \\
\text { average (standard deviation) of: } \\
\text { height: } 2.3 \mathrm{~m}(2.6 \mathrm{~m}) \\
\text { size }^{1}: 57.7 \mathrm{~m}^{2}\left(39.1 \mathrm{~m}^{2}\right) \\
\text { length }^{1}: 16.5 \mathrm{~m}(13.2 \mathrm{~m}) \\
\text { width }{ }^{1}: 8.0 \mathrm{~m}(7.2 \mathrm{~m}) \\
\text { persons/household }: 4.3(0.9)\end{array}$ & $\begin{array}{l}\text { Detached housing, with a mix of } \\
\text { residential and commercial use. } \\
\text { Low-rise with one to two floors. } \\
\text { Comprised of wood, brickwork, } \\
\text { and reinforced concrete, tin roof. } \\
\text { Often located along small } \\
\text { alleyways or in peri-urban } \\
\text { locations. }\end{array}$ & \\
\hline 2 & $\begin{array}{c}\text { Local-type shophouse } \\
(n=540) \\
\text { average (standard deviation) of: } \\
\text { height: } 3.9 \mathrm{~m}(3.1 \mathrm{~m}) \\
\text { size }^{1}: 85.1 \mathrm{~m}^{2}\left(60.3 \mathrm{~m}^{2}\right) \\
\text { length }^{1}: 16.4 \mathrm{~m}(7.0 \mathrm{~m}) \\
\text { width }^{1}: 7.2 \mathrm{~m}(4.2 \mathrm{~m}) \\
\text { persons/household } \\
\text { p }: 5.8(2.4)\end{array}$ & $\begin{array}{l}\text { Typical building type in Da } \\
\text { Nang. Detached/semi- } \\
\text { detached/terraced shophouse. } \\
\text { It is a two to five story urban } \\
\text { building, which allows for a } \\
\text { shop or other public activity at } \\
\text { the street level, with residential } \\
\text { accommodation on the upper } \\
\text { floors. }\end{array}$ & $\frac{8}{19}$ \\
\hline 3 & $\begin{array}{c}\text { Single family, bungalow } \\
\qquad(n=29) \\
\text { average (standard deviation) of: } \\
\text { height: } 4.0 \mathrm{~m}(1.5 \mathrm{~m}) \\
\text { size }^{1}: 101.6 \mathrm{~m}^{2}\left(55.4 \mathrm{~m}^{2}\right) \\
\text { length }^{1}: 25.1 \mathrm{~m}(16.8 \mathrm{~m}) \\
\text { width }^{1}: 14.5 \mathrm{~m}(9.1 \mathrm{~m}) \\
\text { persons/household }^{2}: 4.7(2.4)\end{array}$ & $\begin{array}{l}\text { Single family detached dwelling, } \\
\text { low-rise, two to three floors, } \\
\text { built from brickwork and } \\
\text { concrete, located in new urban } \\
\text { districts. }\end{array}$ & \\
\hline 4 & $\begin{array}{c}\begin{array}{c}\text { Single family, villa } \\
(n=39)\end{array} \\
\text { average (standard deviation) of: } \\
\text { height: } 5.1 \mathrm{~m}(3.7 \mathrm{~m}) \\
\text { size }^{1}: 211.8 \mathrm{~m}^{2}\left(174.1 \mathrm{~m}^{2}\right) \\
\text { length }^{1}: 21.8 \mathrm{~m}(8.5 \mathrm{~m}) \\
\text { width }^{1}: 13.1 \mathrm{~m}(5.3 \mathrm{~m}) \\
\text { persons/household } \\
\text { p }: 4.3(1.6)\end{array}$ & $\begin{array}{c}\text { Mostly a single-family detached } \\
\text { dwelling, sometimes two to } \\
\text { three attached multifamily } \\
\text { buildings, low rise, } \\
\text { two to four floors, built from } \\
\text { brickwork } \\
\text { or concrete, located in newly } \\
\text { developed urban areas. }\end{array}$ & \\
\hline 5 & $\begin{array}{l}\text { Multifamily, local }(n=53) \\
\text { average (standard deviation) of: } \\
\text { height: } 5.5 \mathrm{~m}(4.8 \mathrm{~m}) \\
\text { size }^{1}: 346.2 \mathrm{~m}^{2}\left(249.1 \mathrm{~m}^{2}\right) \\
\text { length }^{1}: 30.3 \mathrm{~m}(14.1 \mathrm{~m}) \\
\text { width }^{1}: 14.6 \mathrm{~m}(7.3 \mathrm{~m}) \\
\text { persons/household }^{2}: 5.0(1.8)\end{array}$ & $\begin{array}{l}\text { Multistory/multiunit apartments } \\
\text { with more than three units. } \\
\text { Commercial and/or public usage } \\
\text { is possible. Traditional style of } \\
\text { construction and local } \\
\text { inhabitants. }\end{array}$ & 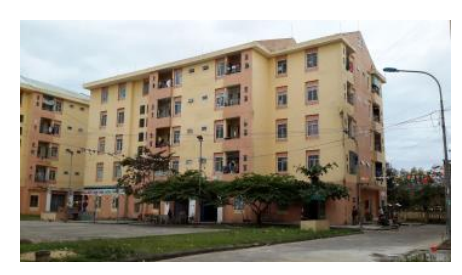 \\
\hline 6 & 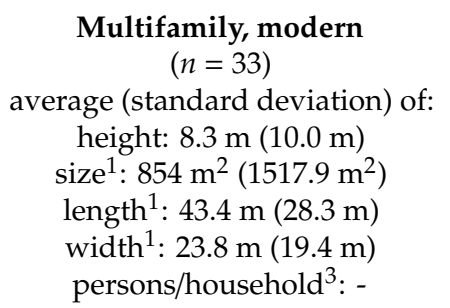 & $\begin{array}{l}\text { Multistory/multiunit apartments } \\
\text { with more than three units. } \\
\text { Modern style of construction. } \\
\text { This class only contains hotels } \\
\text { and other mixed-use commercial } \\
\text { buildings with non-local } \\
\text { residents. }\end{array}$ & \\
\hline
\end{tabular}


Table 1. Cont.

\begin{tabular}{|c|c|c|c|}
\hline ID & Building Type and Statistics & Description & Representative Reference Picture \\
\hline 7 & $\begin{array}{c}\text { Special structure/other } \\
(n=11) \\
\text { average (standard deviation) of: } \\
\text { height: } 5.4 \mathrm{~m}(5.0 \mathrm{~m}) \\
\text { size }^{1}: 552.1 \mathrm{~m}^{2}\left(928 \mathrm{~m}^{2}\right) \\
\text { length }^{1}: 39.3 \mathrm{~m}(24.0 \mathrm{~m}) \\
\text { width }^{1}: 22.1 \mathrm{~m}(14.8 \mathrm{~m}) \\
\text { persons/household }{ }^{3}:-\end{array}$ & $\begin{array}{l}\text { Wide range of built-up } \\
\text { structures with a predominant } \\
\text { non-residential use. }\end{array}$ & \\
\hline 8 & $\begin{array}{c}\text { Hall }(n=17) \\
\text { average (standard deviation) of: } \\
\text { height: } 5.1 \mathrm{~m}(3.8 \mathrm{~m}) \\
\text { size }^{1}: 917.6 \mathrm{~m}^{2} \\
\left(1654.0 \mathrm{~m}^{2}\right) \text { length }{ }^{1}: 44.3 \mathrm{~m}(31.4 \\
\mathrm{m}) \\
\text { width }^{1}: 22.8 \mathrm{~m}(15.8 \mathrm{~m}) \\
\text { persons/household }^{3}:-\end{array}$ & $\begin{array}{c}\text { Large buildings with one to } \\
\text { multiple stores, non-residential } \\
\text { use. Mostly markets, } \\
\text { warehouses or industrial } \\
\text { buildings. }\end{array}$ & \\
\hline 9 & $\begin{array}{l}\text { Outbuilding/shack }(n=16) \\
\text { average (standard deviation) of: } \\
\text { height: } 2.3 \mathrm{~m}(2.7 \mathrm{~m}) \\
\text { size }^{1}: 94.0 \mathrm{~m}^{2}\left(144.8 \mathrm{~m}^{2}\right) \\
\text { length }^{1}: 16.8 \mathrm{~m}(17.0 \mathrm{~m}) \\
\text { width }^{1}: 7.9 \mathrm{~m}(4.6 \mathrm{~m}) \\
\text { persons/household }{ }^{3}:-\end{array}$ & $\begin{array}{c}\text { A small, often rundown, } \\
\text { non-residential building or an } \\
\text { outbuilding with non-residential } \\
\text { usage (e.g., storage, bicycle } \\
\text { racks). }\end{array}$ & \\
\hline
\end{tabular}

${ }^{1}$ as retrieved from the footprints of the surveyed buildings as described in Section $2.3{ }^{2}$ as retrieved from the data collection conducted by Vetter-Gindele et al. (2019) [3]; ${ }^{3}$. not assessed.

\subsection{External Data}

To add a spatial relation to the identified changes, administrative boundaries were retrieved from the database of global administrative areas (GADM, [11]) which divides the study area into eight districts and 51 wards, of which 50 belong to Da Nang and one belongs to the adjacent Quảng Nam province. We use the wards as an administrative division of the city into homogenous units of analysis.

As a measure which is independent from political divisions, hexagonal cells with a width of $250 \mathrm{~m}$ were computed. Compared to squared measures, hexagons are more suitable to represent nearest neighbor areas, reduce the sampling bias at the edges and are reportedly easier to interpret by the human eye [12]. Both measures allow for a detailed and precise analyses of the city without violating the personal property rights of the residents or house owners.

\subsection{Data Processing and Change Detection}

The delineation of built-up areas and the extraction of building heights from the Pléiades image of 2015 was conducted using an object-based image analysis approach, as described by Warth et al. [4]. As described in that study, built-up areas were identified using a multiresolution segmentation. This segmentation was based on the four spectral bands of the acquisition, their three principal components, a Canny edge detection algorithm [13], and a digital surface model retrieved from the tri-stereoscopic information of the Pléiades product [14]. The image objects were then classified into "built-up" and "non-built-up" using rule-based thresholds applied to the derived object features, resulting in an accuracy of $88.4 \%$. All built-up areas were divided into single buildings using spatial intersection with cadastral boundaries and visual identification, as described by Vetter-Gindele et al. (2019) [3]. The geometric accuracy of single buildings was assessed by the manual digitization of 50 randomly selected 
buildings, whose areas were then compared to the automatically derived building footprints. The comparison resulted in an overall agreement of $87.2 \%$. While accuracies of over $95 \%$ were achieved for buildings of average sizes (50-160 $\left.\mathrm{m}^{2}\right)$, larger underestimations were observed for very small $\left(<50 \mathrm{~m}^{2}\right)$ and very large $\left(>200 \mathrm{~m}^{2}\right)$ buildings, which only make up a small fraction of the buildings in Da Nang. In the end, the derived footprints resulted in building areas which were found to be reliable enough to serve as one of the variables for the classification of building types in the next step.

Accordingly, building types were assigned based on the criteria given in Table 1 and manual refinement. This classification typology resulted in an overall number of 241,217 building features in the study area for the year 2015. To understand the quality of the building type classification, an accuracy assessment was conducted based on the 803 building references which were collected during the field campaign, as described in Section 2.3 [3]. The confusion matrix between the reference data and the classified building types is shown in Table A1 in the Appendix A and discussed in more detail in Section 3.5. An overall classification accuracy of $90.9 \%$ was achieved.

In the next step, a typology of changes was developed, consisting of five classes (Table 2): no change (1), construction of a new building (2), changes in the building, e.g., roof color or size, while maintaining the building type according to Table 1 (3), upgrading of the building to a new building type, mostly of higher quality (4), and demolition of the building (5). All buildings identified for the year 2015 were then examined for changes by a visual comparison of the two images and one type of change was assigned to each feature. In the case of a newly constructed building, a new feature was manually digitized at this location. This resulted in a total number of 260,608 buildings for 2017, which indicates an increase of 19,391 for the investigated area.

The process of visual interpretation was conducted by independent persons, with additional quality control by another person to ensure the highest level of objectivity and to minimize errors of omission and commission. However, as demonstrated by Figure 3, the identification of changes can still be subject to the interpreter's perception of the two images and their ability to identify changes. This was especially challenging in densely built-up areas where buildings stand extremely close (Figure 4, left part). This required a more time-consuming inspection and an independent crosscheck in those areas. For the more regular parts of Da Nang (Figure 4, right part) changes were clearly visible and unambiguous.

The selection of a manual assignment of building types for 2017 and the derivation of the corresponding changes was considerably faster than repeating the semi-automated building classification as it was conducted for the image of 2015. At the same time, it allowed us to achieve higher accuracies in the final data product-for example, by manually correcting smaller misclassifications of the building types of 2015 while searching for changes between both images.

Table 2. Definition of changes and examples for the two satellite images used in this study.

\begin{tabular}{|c|c|c|c|}
\hline ID & Change & Example 2015 & Example 2017 \\
\hline 1 & No change & & \\
\hline 2 & New building & & \\
\hline
\end{tabular}


Table 2. Cont.

\begin{tabular}{|c|c|c|c|}
\hline ID & Change & Example 2015 & Example 2017 \\
\hline 3 & $\begin{array}{l}\text { Change/renovation } \\
\text { without a significant } \\
\text { change in the building } \\
\text { type or footprint }\end{array}$ & & \\
\hline 4 & $\begin{array}{l}\text { Upgrading including } \\
\text { a significant change in } \\
\text { the building } \\
\text { type/footprint }\end{array}$ & & \\
\hline 5 & $\begin{array}{l}\text { Demolition of the } \\
\text { building }\end{array}$ & & \\
\hline
\end{tabular}

In the final step, the building types and their changes between 2015 and 2017 were summarized for each ward (Figure 4, black dashed lines) and hexagon (Figure 4, blue lines). As described in Table 3, each polygon contains attributes on the absolute number of buildings for both years, as well as the absolute and relative amount of change.
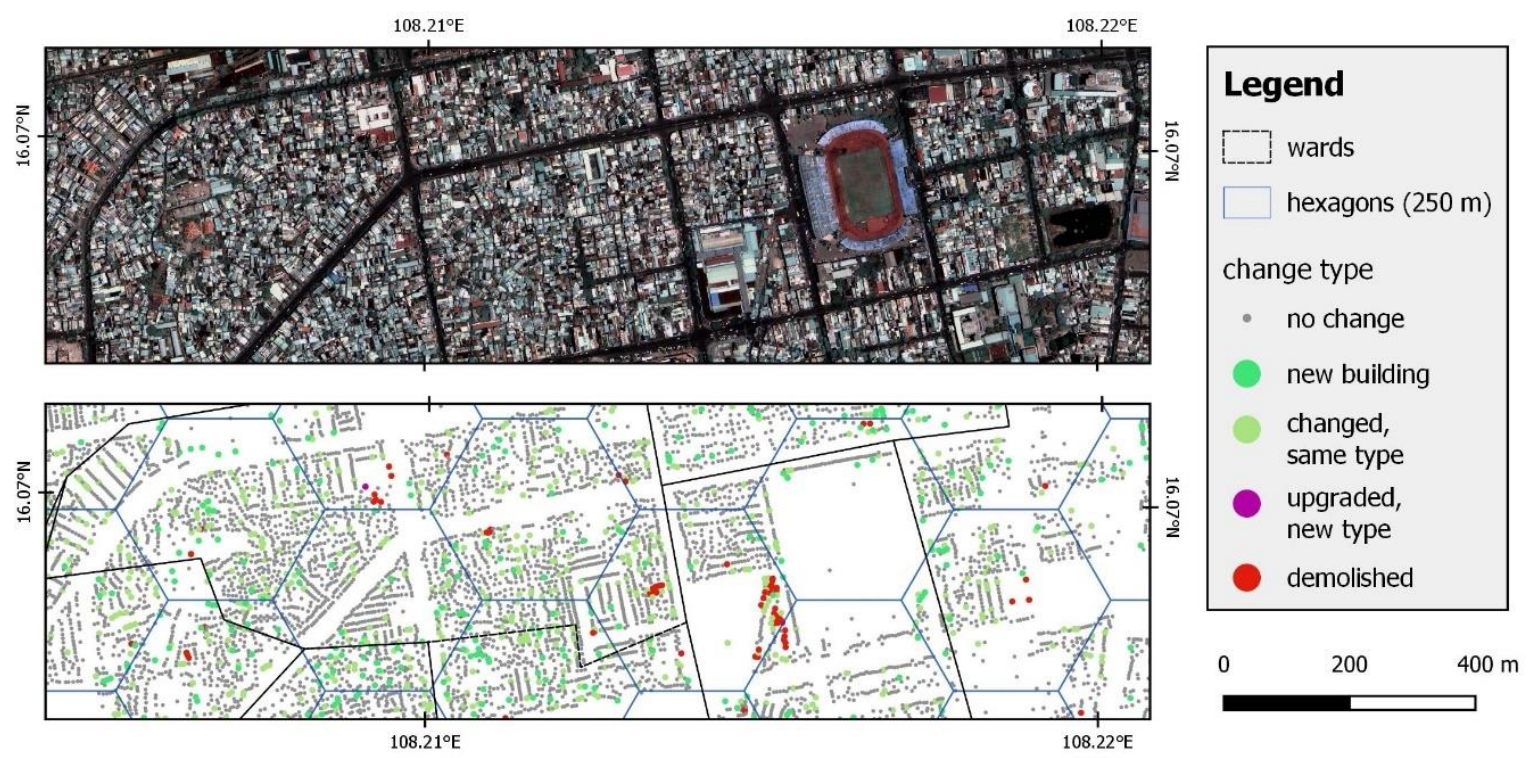

Figure 4. Example for Hòa Minh ward. Top: satellite image from 2017; bottom: result of the visual identification of changes, including the boundaries of administrative wards and hexagons.

\section{Data Description}

\subsection{Datatype}

The two datasets presented in this descriptor (please see the zip file in the Supplementary Materials) will be described in the next sections and the changes in the building stock for the urban areas of Da Nang city, aggregated by administrative wards and a systematic grid of hexagon of $250 \mathrm{~m}$ in width, 
will be explained. Both are stored as vector datasets in the ESRI shapefile format, which is compatible with common Geographic Information Systems (GIS), such as QGIS or ArcMap. Each dataset consists of several separate files with the same name, but different extensions: a vector geometry ( ${ }^{*}$.shp), an attribute table $\left({ }^{*}\right.$.dbf), a projection file $\left({ }^{*}\right.$.prj), and an index linking the attribute table to the geometries (*.shx). Both datasets are stored in the UTM coordinate system, zone 49N (EPSG: 32649). The encoding of the attribute table $\left({ }^{*} . \mathrm{cpg}\right)$ is UTF- 8 to support the correct display of Vietnamese characters.

\subsection{Data Structure}

Table 3 summarizes the attributes contained by the administrative (adm) and hexagonal (hex) datasets. Both datasets contain the absolute number of changes ( $c 1$ to c5, as defined in Table 2), the absolute number of buildings per year and type (t2015_1 to t2017_9, as defined in Table 1), as well as the absolute (nc) number of changes per building type in each ward and hexagon. The relative number of changes $(\mathrm{pc})$ denotes the share of the changes in one building type compared to the total number of changes in the reference area. For the administrative dataset, the results can also be summarized by district, using the respective attributes (dist_ID or district). As one suggestion for further spatial analyses, the hexagon dataset additionally contains an attribute named dist_mean, which defines the Euclidean distance of each hexagon from the historic city center in Hải Châu district. This will be discussed in Section 3.4.

Table 3. Attributes of the two shapefiles.

\begin{tabular}{|c|c|c|c|c|}
\hline Attribute & Description & adm & hex & Source \\
\hline province & name of the province & $\mathrm{x}$ & & GADM \\
\hline dist_ID & id of the district & $x$ & & GADM \\
\hline district & name of the district & $x$ & & GADM \\
\hline ward_ID & id of the ward & $x$ & & GADM \\
\hline ward & name of the ward & $\mathrm{x}$ & & GADM \\
\hline ward_en & name of the ward without special characters & $x$ & & GADM \\
\hline area & area of the ward in square kilometers & $x$ & & GIS analysis \\
\hline per_cover & $\%$ of ward area covered by satellite & $\mathrm{x}$ & & GIS analysis \\
\hline hex_ID & id of the hexagon & & $x$ & GIS analysis \\
\hline dist_mean & mean distance from the historic city center & & $x$ & GIS analysis \\
\hline c1 & no of buildings with no-change & $\mathrm{x}$ & $\mathrm{x}$ & Satellite image \\
\hline c2 & no. of new buildings & $x$ & $x$ & Satellite image \\
\hline c3 & no. of changed buildings (same type) & $x$ & $\mathrm{x}$ & Satellite image \\
\hline$c 4$ & no. of upgraded buildings (other type) & $x$ & $x$ & Satellite image \\
\hline c5 & no. of demolished buildings & $x$ & $x$ & Satellite image \\
\hline c_sum & no. of all changed buildings & $x$ & $x$ & $c 2+c 3+c 4+c 5$ \\
\hline t2015_1 & no. of "basic" buildings in 2015 & $x$ & $x$ & Satellite image \\
\hline t2015_2 & no. of "local-type shophouse" buildings in 2015 & $x$ & $x$ & Satellite image \\
\hline t2015_3 & no. of "bungalow" buildings in 2015 & $x$ & $x$ & Satellite image \\
\hline t2015_4 & no. of "villa-type" buildings in 2015 & $x$ & $\mathrm{x}$ & Satellite image \\
\hline t2015_5 & no. of "apartment, local" buildings in 2015 & $x$ & $x$ & Satellite image \\
\hline t2015_6 & no. of "apartment, modern" buildings in 2015 & $x$ & $x$ & Satellite image \\
\hline t2015_7 & no. of "hall" buildings in 2015 & $x$ & $x$ & Satellite image \\
\hline t2015_8 & no. of "outbuilding" buildings in 2015 & $x$ & $\mathrm{x}$ & Satellite image \\
\hline t2015_9 & no. of "special" buildings in 2015 & $x$ & $\mathrm{x}$ & Satellite image \\
\hline t2015_sum & no. of all buildings in 2015 & $x$ & $x$ & $\operatorname{sum}(\mathrm{t} 2015)$ \\
\hline t2017_1 & no. of "basic" buildings in 2017 & $x$ & $\mathrm{x}$ & Satellite image \\
\hline t2017_2 & no. of "local-type shophouse" buildings in 2017 & $x$ & $\mathrm{x}$ & Satellite image \\
\hline t2017_3 & no. of "bungalow" buildings in 2017 & $x$ & $x$ & Satellite image \\
\hline t2017_4 & no. of "villa-type" buildings in 2017 & $x$ & $x$ & Satellite image \\
\hline t2017_5 & no. of "apartment, local" buildings in 2017 & $x$ & $x$ & Satellite image \\
\hline t2017_6 & no. of "apartment, modern" buildings in 2017 & $x$ & $x$ & Satellite image \\
\hline t2017_7 & no. of "hall" buildings in 2017 & $\mathrm{x}$ & $\mathrm{x}$ & Satellite image \\
\hline t2017_8 & no. of "outbuilding" buildings in 2017 & $x$ & $\mathrm{x}$ & Satellite image \\
\hline t2017_9 & no. of "special" buildings in 2017 & $x$ & $x$ & Satellite image \\
\hline t2017_sum & no. of all buildings in 2017 & $x$ & $\mathrm{x}$ & sum(t2017) \\
\hline
\end{tabular}


Table 3. Cont.

\begin{tabular}{|c|c|c|c|c|}
\hline Attribute & Description & adm & hex & Source \\
\hline nc_t1 & net change in "basic" buildings & $\mathrm{x}$ & $\mathrm{x}$ & t2017_1-t2015_1 \\
\hline nc_t2 & net change in "local-type shophouse" buildings & $x$ & $x$ & t2017_2-t2015_2 \\
\hline nc_t3 & net change in "bungalow" buildings & $x$ & $x$ & t2017_3-t2015_3 \\
\hline nc_t4 & net change in "villa-type" buildings & $x$ & $x$ & t2017_4-t2015_4 \\
\hline nc_t5 & net change in "apartment, local" buildings & $x$ & $x$ & t2017_5-t2015_5 \\
\hline nc_t6 & net change in "apartment, modern" buildings & $\mathrm{x}$ & $x$ & t2017_6-t2015_6 \\
\hline nc_t7 & net change in "hall" buildings & $\mathrm{x}$ & $x$ & t2017_7-t2015_7 \\
\hline nc_t8 & net change in "outbuilding" buildings & $x$ & $x$ & t2017_8-t2015_8 \\
\hline nc_t 9 & net change in "special" buildings & $x$ & $x$ & t2017_9-t2015_9 \\
\hline nc_all & net change in all buildings & $\mathrm{x}$ & $x$ & t2017_sum-t2015_sum \\
\hline pc_t1 & $\%$ of change in "basic" buildings & $x$ & $x$ & nc_t1/t2015_1 \\
\hline pc_t2 & $\%$ of change in "local-type shophouse" buildings & $x$ & $x$ & nc_t2/t2015_2 \\
\hline pc_t3 & $\%$ of change in "bungalow" buildings & $\mathrm{x}$ & $x$ & nc_t3/t2015_3 \\
\hline pc_t4 & $\%$ of change in "villa-type" buildings & $x$ & $x$ & nc_t4/t2015_4 \\
\hline pc_t5 & $\%$ of change in "apartment, local" buildings & $x$ & $x$ & nc_t5/t2015_5 \\
\hline pc_t6 & $\%$ of change in "apartment, modern" buildings & $\mathrm{x}$ & $\mathrm{x}$ & nc_t6/t2015_6 \\
\hline pc_t7 & $\%$ of change in "hall" buildings & $x$ & $x$ & nc_t7/t2015_7 \\
\hline pc_t8 & $\%$ of change in "outbuilding" buildings & $x$ & $x$ & nc_t8/t2015_8 \\
\hline pc_t9 & $\%$ of change in "special" buildings & $\mathrm{x}$ & $x$ & nc_t9/t2015_9 \\
\hline pc_all & $\%$ of changed buildings based on all buildings in 2015 & $x$ & $\mathrm{x}$ & c_sum/t2015_sum \\
\hline
\end{tabular}

Accordingly, the dataset does not contain any data related to individuals collected during the field campaigns. The attributes are purely a result of the geospatial analyses described in the methodology section. This aggregation grants that no user can calculate the original building or plot geometries, nor their exact type or location.

\subsection{Administrative Level}

The dataset $<$ DaNang_buildings_adm_UTM49N $>$ contains the changes in the building stock aggregated by wards. These represent the official administrative units, so this dataset is best compatible with other socio-demographic data, such as the official Vietnam Population and Housing Census released by the General Statistics Office of Vietnam [15]. However, it must be kept in mind that, in particular, the wards at the edges are not entirely covered by the satellite images, so absolute numbers have to be interpreted with care. For this reason, the attribute table of the administrative dataset contains an additional attribute, "per_cover", which tells the percentage of each ward's area inside the AOI. It is illustrated in Figure A1 in the Appendix B, which highlights the ten wards which are only covered by $70 \%$ or less of the satellite images.

Figure 5 shows the dominance of new construction activities over demolitions in the observed time between 2015 and 2017. Except for the already very densely built-up wards of An Hải Đông, Bình Hiên, and Phước Ninh, which are located near the city center, and the rural wards of Hòa Vang district in the western outskirts of the city, all parts of Da Nang have experienced a considerable increase in building numbers, mostly exceeding 500 new buildings per ward. In contrast, the number of demolitions is visibly lower throughout the city. Over $90 \%$ of all wards range between 10 and 200 demolished buildings. Of course, these numbers are strongly dependent on the size of a ward. For this reason, the attribute "area" is contained in the dataset to calculate the absolute changes per square kilometer (c1/area or c5/area), as shown in Figure 6, which gives a more representative picture for each ward. It highlights the increase in Hòa Minh in the north and the relative high demolitions in Hải Châu district, representing the historic city center with its extreme building density. Another method of calculating a spatially uncorrelated representation of changes is given by the hexagons described in Section 3.4. 

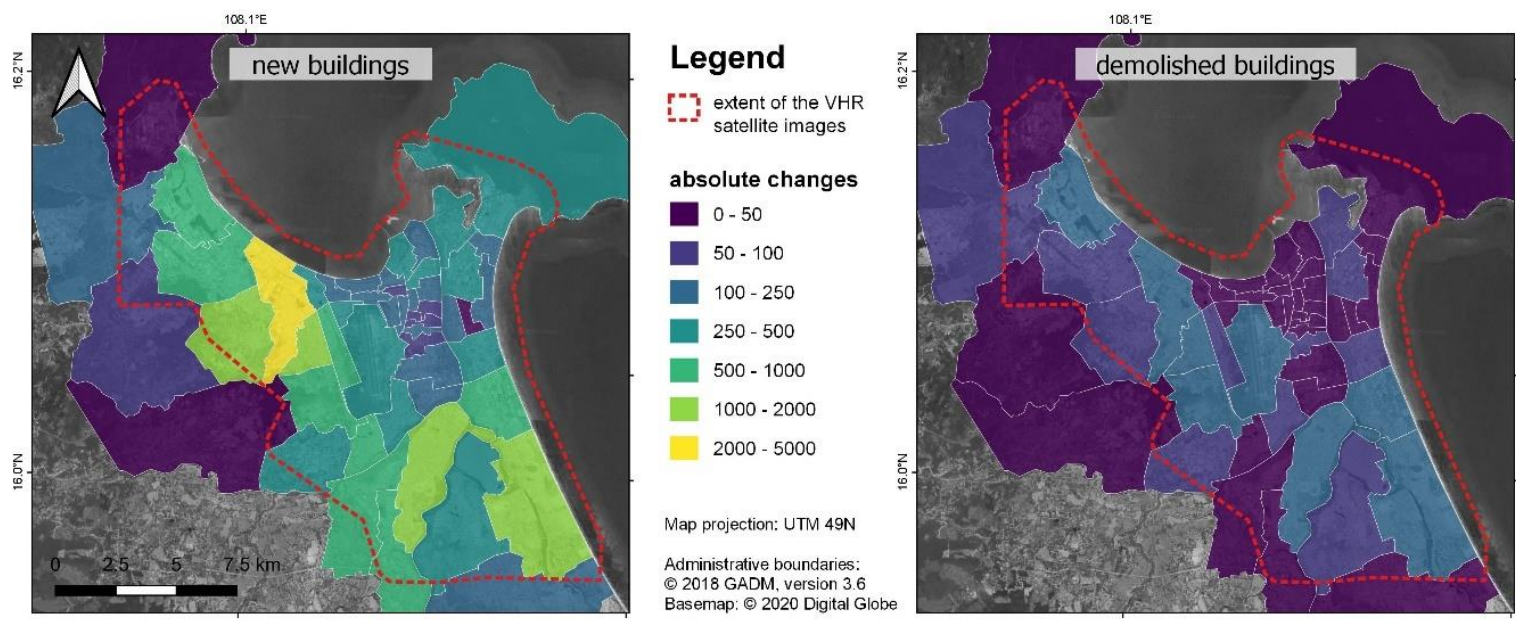

Figure 5. Absolute building changes between 2015 and 2017: new buildings (c2, left) and demolitions (c5, right).
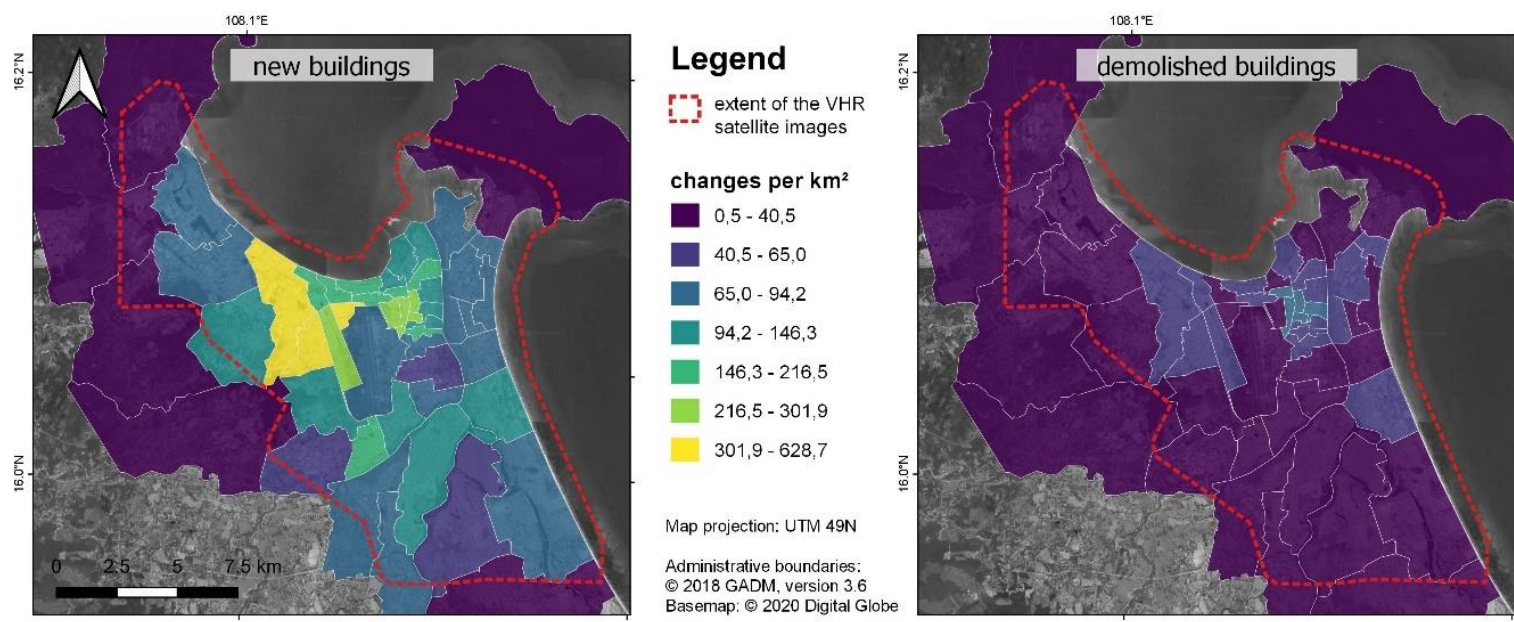

Figure 6. Changes per square kilometer between 2015 and 2017: new buildings (c2, left) and demolitions (c5, right).

Figure 7 demonstrates further spatial patterns revealed in the data: It shows that multifamily apartments largely increased between 2015 and 2017, but with spatially distinct patterns. While local-type apartments (building type 5 in Table 2), which are predominantly inhabited by local people, show indifferent patterns and even slight decreases in the outer wards, there is a tremendous increase in hotels (modern-type apartments, building type 6 in Table 2) along the coasts in the east (Ngũ Hành Sơn district) and in the north (Liên Chiểu district), which underlines Da Nang's ambitions to increase its touristic sector [16].

However, as already stated above, the size of the wards largely differs and ranges between 0.23 and 47 square kilometers, with an average ward size of 7.1 square kilometers. Accordingly, absolute building numbers and their changes are spatially biased by the ward size. For this reason, a second dataset is introduced, which provides a regular representation of the aggregated results. 

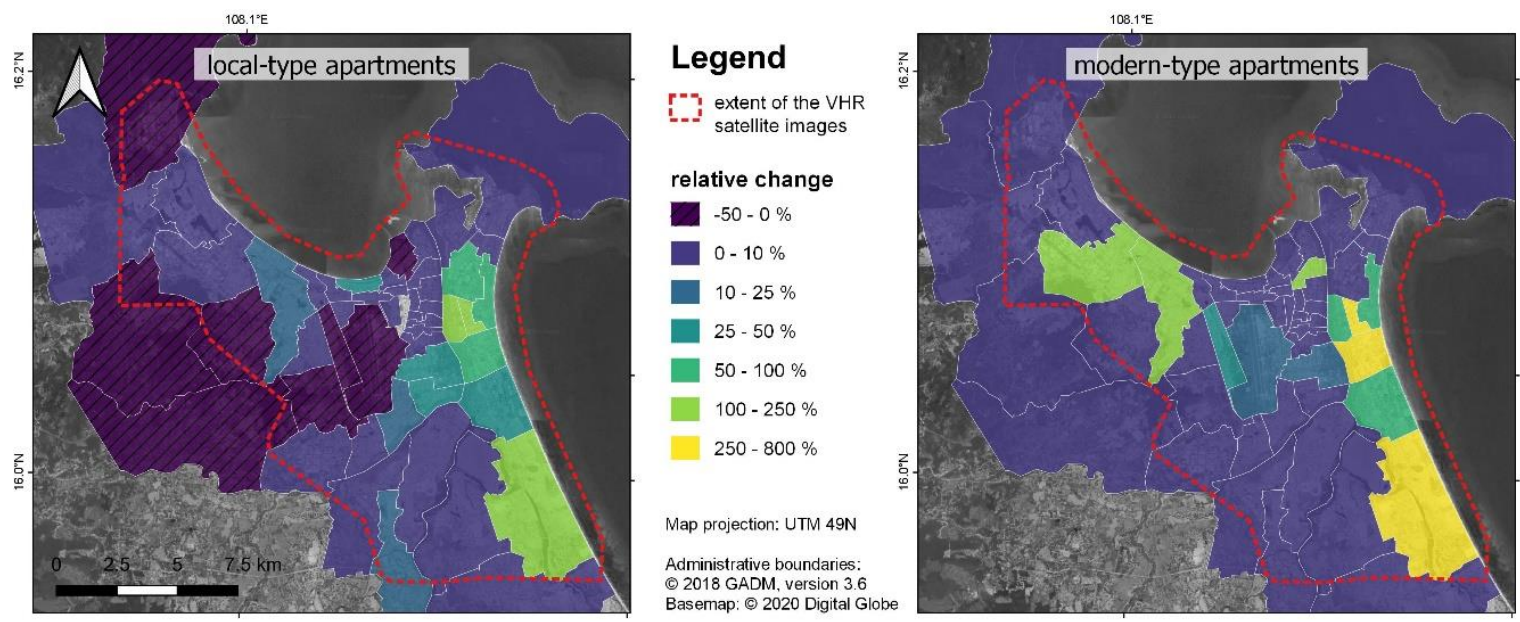

Figure 7. Relative increase in local (pc_t5, left) and modern (pc_t6, right) apartments between 2015 and 2017 per ward.

\subsection{Spatial Aggregation}

The dataset $<$ DaNang_buildings_hex250m_UTM49N.shp $>$ aggregates the changes at a spatially regular grid, where each hexagon has a width of $250 \mathrm{~m}$ and encloses an area of 72 hectares. This allows us to identify patterns that are not related to administrative boundaries. As an example, Figure 8 shows the absolute differences in bungalows and villa-type buildings calculated by the following equations: t2017_3-t2015_3 and t2017_4-t2015_4. It shows that these building types and their changes are not drastically shaping the morphology of the city, as most of the hexagons have values close to zero. However, it also shows that most of the bungalows were demolished in the new urban development areas of Hòa Xuân (Cẩm Lệ district) and Hòa Quy (Ngũ Hành Sơn district) in the southwest of the city center, which is one of Da Nang's fastest urbanizing areas. Large masses of sand were piled to create new space for development at a confluence area of the Hán River. In turn, most of the new villa-type buildings are constructed along the coastal area in the east to increase the number of holiday residences.
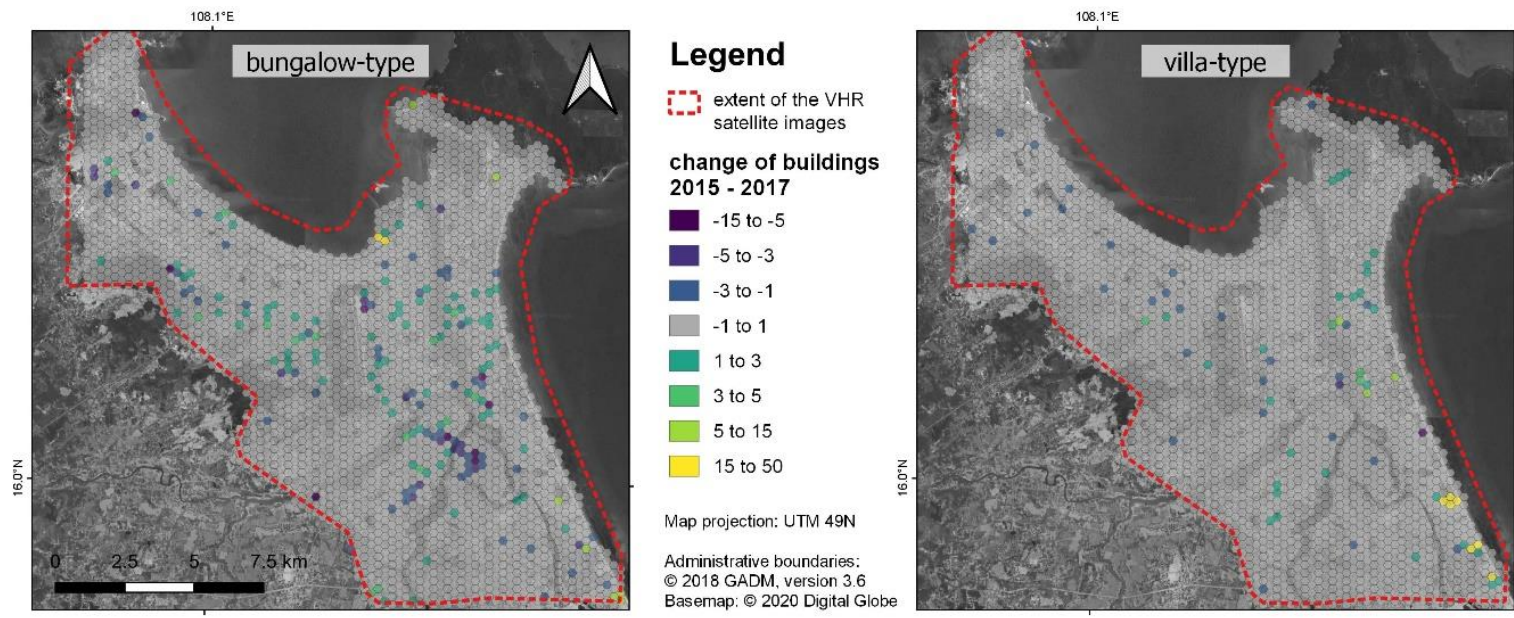

Figure 8. Absolute change in bungalow-type (left) and villa-type (right) buildings between 2015 and 2017.

The notable increase in buildings in Cam Le Cẩm Lệ is furthermore underlined by Figure 9, where two hotspots of new buildings (change type 2 as defined in Table 1) are visible: these are the wards of An Khê, Hòa Phát, and Hòa Minh in the north and the new construction areas in Hòa Xuân ward of Cẩm Lệ district enclosed by the Hàn River in the southwest. In particular, the increase in built-up areas in Cẩm Lệ was already confirmed in 2016 by Bachofer and Rau [17] and Linh and Chuong [18]. 
This is especially alarming because these new residential areas are expected to lie below the tideline in 2050 [19] (Figure A3). In turn, most of the building changes (within the same type, change type 3 as defined in Table 1) occurred in the districts Hải Châu and Ngũ Hành Sơn, around the historic center of Da Nang. These are the parts of the city which are already extremely dense (Figure A2) and probably do not allow large increases in the building stock. Instead, additional parts or floors were added to the existing ones.
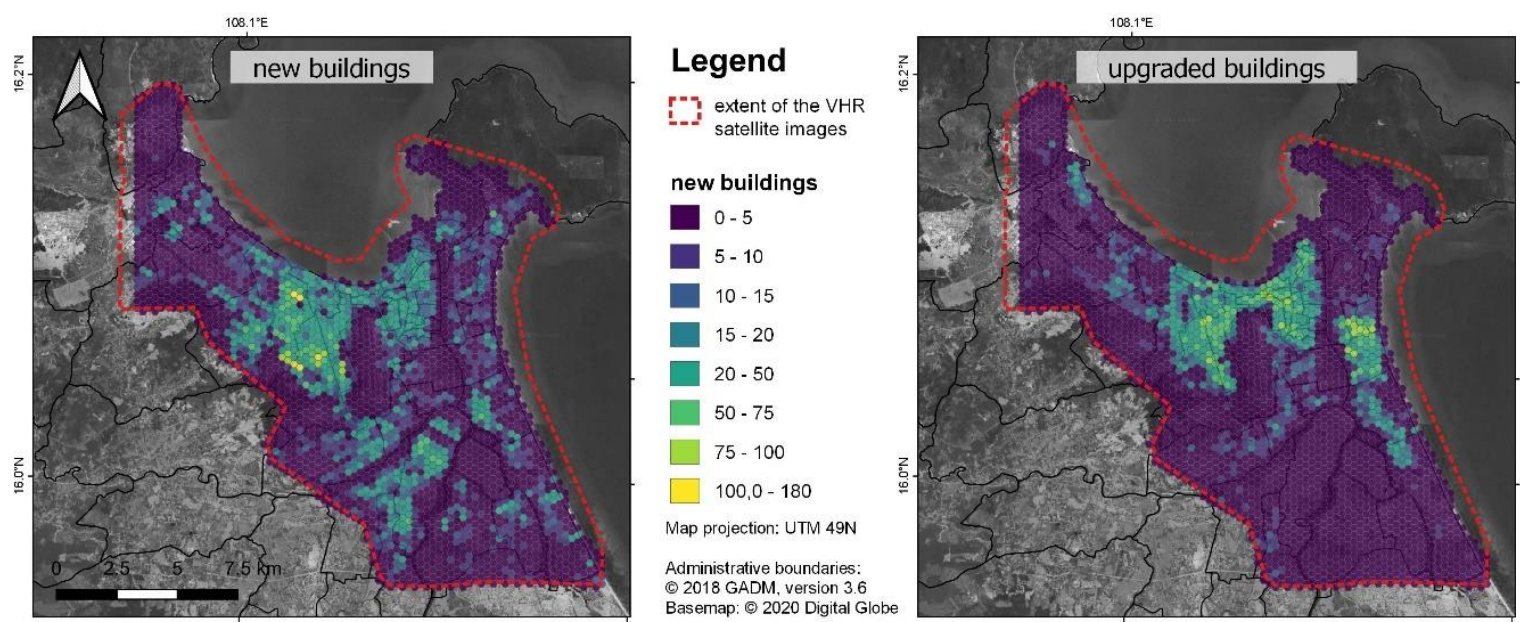

Figure 9. Number of new (c2, left) and changed (c3, right) buildings between 2015 and 2017.

To furthermore demonstrate the value of the presented dataset, we compared the number of demolitions displayed by the hexagonal aggregation to the demolitions automatically identified by Warth et al. (2019), who derived digital surface models of the city from 2015 and 2017 to detect demolitions based on the threshold of the height difference [4]. However, they used hexagons with a diameter of $500 \mathrm{~m}$, so both datasets were normalized by calculating the demolitions per square kilometer. As shown in Figure 10, the presented dataset not only offers finer spatial details, which make it more suitable to describe urban changes, but is also less prone to systematic overestimation, as it was reported by Warth et al. (2019) [4].
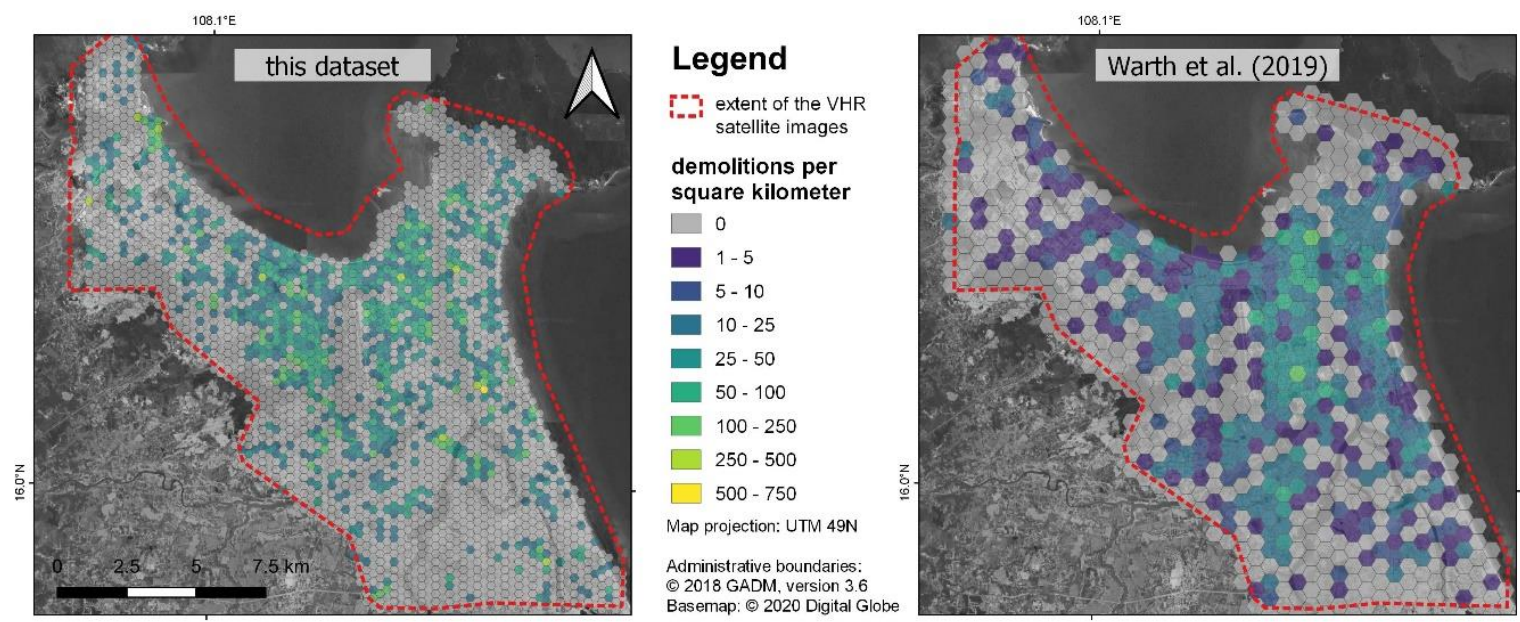

Figure 10. Demolitions per square kilometer in the presented dataset (left) compared to findings of Warth et al. (2019).

\subsection{Statistical Description}

Lastly, we highlight the potential for statistical analyses of the prepared data, which can be conducted based on the attribute tables of the shapefiles. Figure 11 aggregates the changes at the 
building level for seven districts covered by the satellite images (please note that Điện Bàn district was excluded because of very low coverage and small values). It highlights the enormous share of changes in the total building stock of the city.

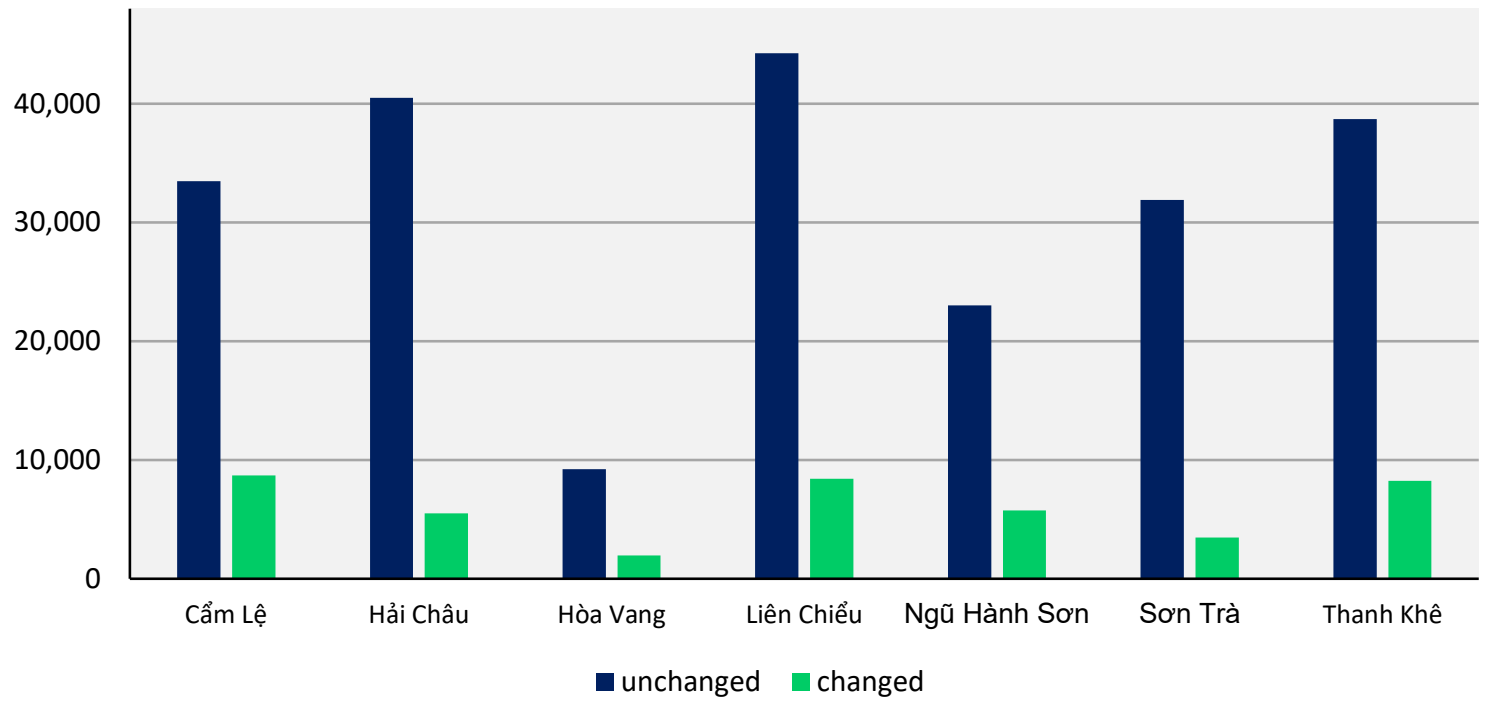

Figure 11. Changed and unchanged buildings for the districts in Da Nang.

Figure 12 shows the proportion of new and demolished buildings based on the hexagon dataset, in relation to their average distance to the historic city center of Da Nang. Interestingly, both types of changes show a similar pattern, even if they are not displayed in absolute values. Accordingly, 50\% of all new buildings and 43\% of all demolitions between 2015 and 2017 occurred within a distance of three to six kilometers from the historic city center. Within a radius of two kilometers, $12.9 \%$ of new buildings were built, but $21.2 \%$ of demolitions occurred. This again underlines that the central residential areas in Da Nang are already very dense and do not allow much more growth. Instead, the amount of changed buildings (change type 3, as defined in Table 1) is visibly higher in the more central areas. Of all changed buildings in Da Nang, 77\% were located within the first six kilometers.

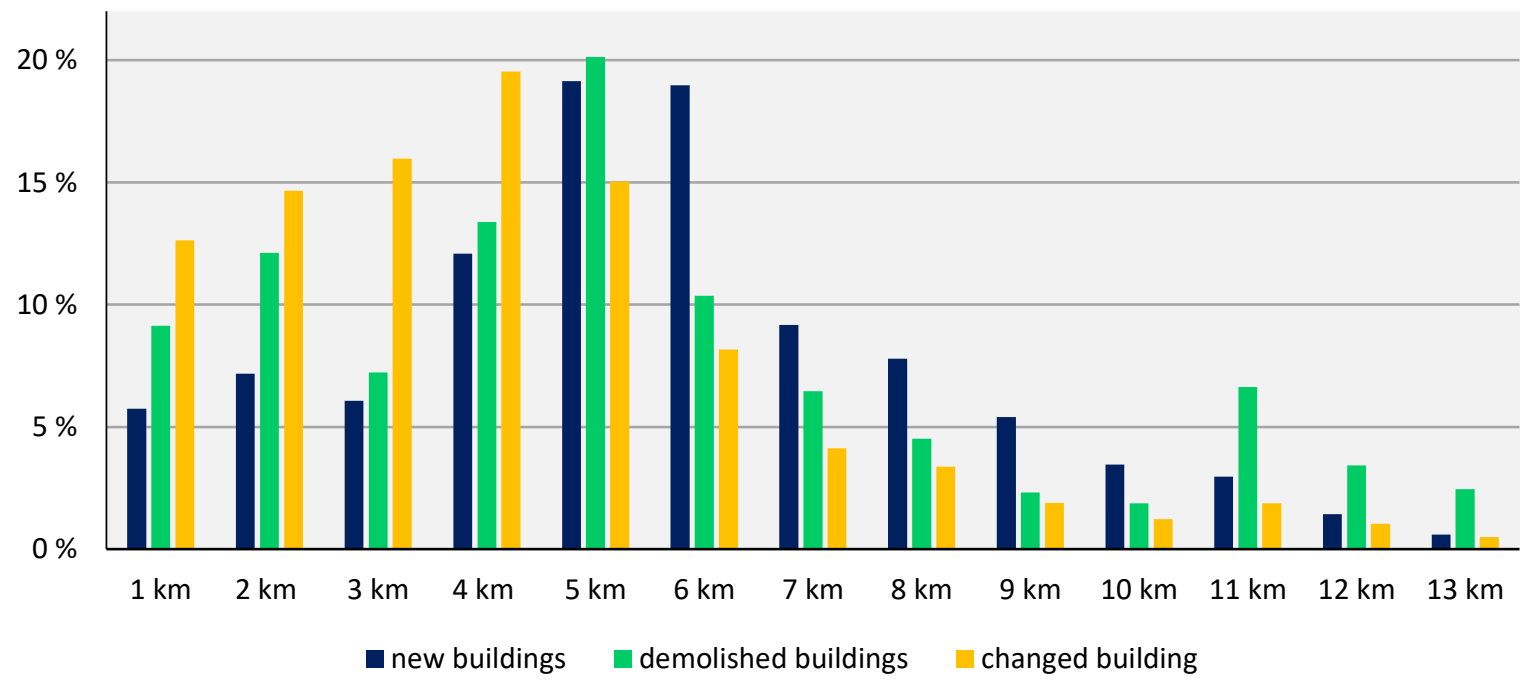

Figure 12. Share of new and demolished buildings with respect to the distance to the historic city center.

\subsection{Discussions on Data Quality}

This section summarizes the most important aspects concerning accuracy. It is obvious that the quality of the presented dataset depends upon two major error sources: the first is the accuracy of all 
input products, which determines how well the changes between 2015 and 2017 can be identified and classified. If buildings were not identified or classified for 2015, it is likely that an error is propagated into the change detection approach. As reported by Warth et al. [4], the built-up areas of 2015 have been assessed at an accuracy of $88.4 \%$. Accordingly, the actual size of an individual building triggers potential errors. This affects small buildings in the first instance, because they are more sensitive to misclassifications of small image objects. We did not see a propagation of this error into later products, as the quality of building areas was assessed by Vetter-Gindele et al. [3] and reported with $87.2 \%$ accuracy. As the subsequent classification of building types was also based on the buildings' sizes, assessed from the satellite image, incorrect estimates could result in the assignment of a wrong type. This is partly disproved by the confusion matrix shown in Table A1, which shows that most of the misclassifications occurred between buildings of a similar size (e.g., single basic and single local, bungalows and villas, or also multifamily local and multifamily modern). Accordingly, we see a more plausible reason for the incorrect classifications, due to atypical buildings which do not fit into the typology presented in Table 1, rather than due to small errors in the size of their footprint.

One shortcoming of the of the presented accuracy assessment is the statistical dominance of single family local-type buildings. On the one hand, this type makes up $90 \%$ of all buildings in Da Nang and has producer and user accuracy measurements above $95 \%$. On the other hand, the small representation of halls, outbuildings and special buildings allows few conclusions to be drawn about the actual accuracy of these building types, and their low producer accuracies $(54.5 \%, 70.6 \%$ and $75.0 \%)$, indicate that they are rather underestimated in the dataset in favor of more accurate and complete residential buildings and an overall classification accuracy of $90.9 \%$.

However, the chosen approach of visual identification of changes between 2015 and 2017 allowed the interpreters to correct errors in the building type classification of 2015, thereby minimizing misclassifications above the statistically reported accuracy. This leads to the second potential error source of this dataset, which is the subjective interpretation of building types for the image of 2017 and the resulting changes. We tried to minimize the impact of the single interpreter's perception by distributing this task over a broad range of individuals and by cross-checking random buildings to identify systematic errors. Despite this, interpretation errors can still arise from spectral differences in the two images (Figure 3), or in cases where actual changes are overlooked. Accordingly, these errors of omission and commission cannot entirely be avoided. Based on the statistical tests and the considerations above, their impact on the aggregated numbers at an administrative level and the hexagonal grids is considered very small.

Supplementary Materials: The following are available online at: https://doi.org/10.5281/zenodo.3757710.

Author Contributions: Conceptualization, A.B., G.W., F.B., T.T.G.B. and V.H.; methodology, A.B., G.W. and F.B.; data generation, A.B., H.T. and F.B.; validation and data curation, A.B.; writing-original draft preparation, A.B.; writing-review and editing, A.B., G.W., F.B., F.B., T.T.G.B., H.T. and V.H.; visualization, A.B.; supervision and funding acquisition, F.B. and V.H.; All authors have read and agreed to the published version of the manuscript.

Funding: This research was supported by the German Ministry of Education and Research (Bundesministerium für Bildung und Forschung, BMBF) with the research project Rapid Planning, grant numbers 01LG1301J and 01LG1301K.

Acknowledgments: We acknowledge the support of Alice Rühl, Dimitrij Chudinzow, and Sheetal Marathe, who assisted in the collection of the field reference data, and Bianca Deutsch, Carsten Gawlas, Daniel Gruschwitz, Marco Hammer, Sina Pfleiderer, and Sven Endreß, who assisted in the identification of changes.

Conflicts of Interest: The authors declare no conflict of interest. The funders had no role in the design of the study; in the collection, analyses, or interpretation of data, in the writing of the manuscript, or in the decision to publish the results. 


\section{Appendix A. Accuracy Assessment for the Building Dataset of 2015}

Table A1. Confusion matrix of building types (BT) between reference data and the classification.

\begin{tabular}{|c|c|c|c|c|c|c|c|c|c|c|c|c|}
\hline \multicolumn{13}{|c|}{ Reference Data } \\
\hline & & BT1 & BT2 & ВT3 & BT4 & BT5 & BT6 & BT7 & BT8 & ВT9 & Sum & UA \\
\hline \multirow{11}{*}{ 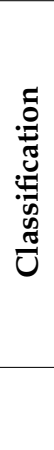 } & BT1 & 57 & 10 & 0 & 0 & 0 & 0 & 0 & 0 & 3 & 70 & $81.4 \%$ \\
\hline & BT2 & 3 & 519 & 3 & 3 & 0 & 0 & 2 & 0 & 1 & 531 & $97.7 \%$ \\
\hline & BT3 & 2 & 6 & 21 & 5 & 0 & 0 & 0 & 0 & 0 & 34 & $61.8 \%$ \\
\hline & BT4 & 0 & 0 & 4 & 28 & 1 & 0 & 0 & 0 & 0 & 33 & $84.8 \%$ \\
\hline & BT5 & 0 & 0 & & 2 & 48 & 6 & 0 & 3 & 0 & 59 & $81.4 \%$ \\
\hline & BT6 & 0 & 0 & 0 & 0 & 4 & 27 & 0 & 2 & 0 & 33 & $81.8 \%$ \\
\hline & BT7 & 0 & 0 & 0 & 0 & 0 & 0 & 6 & 0 & 0 & 6 & $100.0 \%$ \\
\hline & BT8 & 0 & 0 & 0 & 1 & 0 & 0 & 2 & 12 & 0 & 15 & $80.0 \%$ \\
\hline & BT9 & 3 & 5 & 1 & 0 & 0 & 0 & 1 & 0 & 12 & 22 & $54.5 \%$ \\
\hline & sum & 65 & 540 & 29 & 39 & 53 & 33 & 11 & 17 & 16 & 803 & \\
\hline & PA & $87.7 \%$ & $96.1 \%$ & $72.4 \%$ & $71.8 \%$ & $90.6 \%$ & $81.8 \%$ & $54.5 \%$ & $70.6 \%$ & $75.0 \%$ & & $90.9 \%$ \\
\hline
\end{tabular}

$\mathrm{BT}=$ building types $(1=$ single basic; $2=$ single local; $3=$ single bungalow; $4=$ single villa; $5=$ multi local; $6=$ multi modern; 7 = special; $8=$ hall; 9 = outbuilding), $\mathrm{PA}=$ producer's accuracy, $\mathrm{UA}=$ user's accuracy.

\section{Appendix B. Additional Maps}

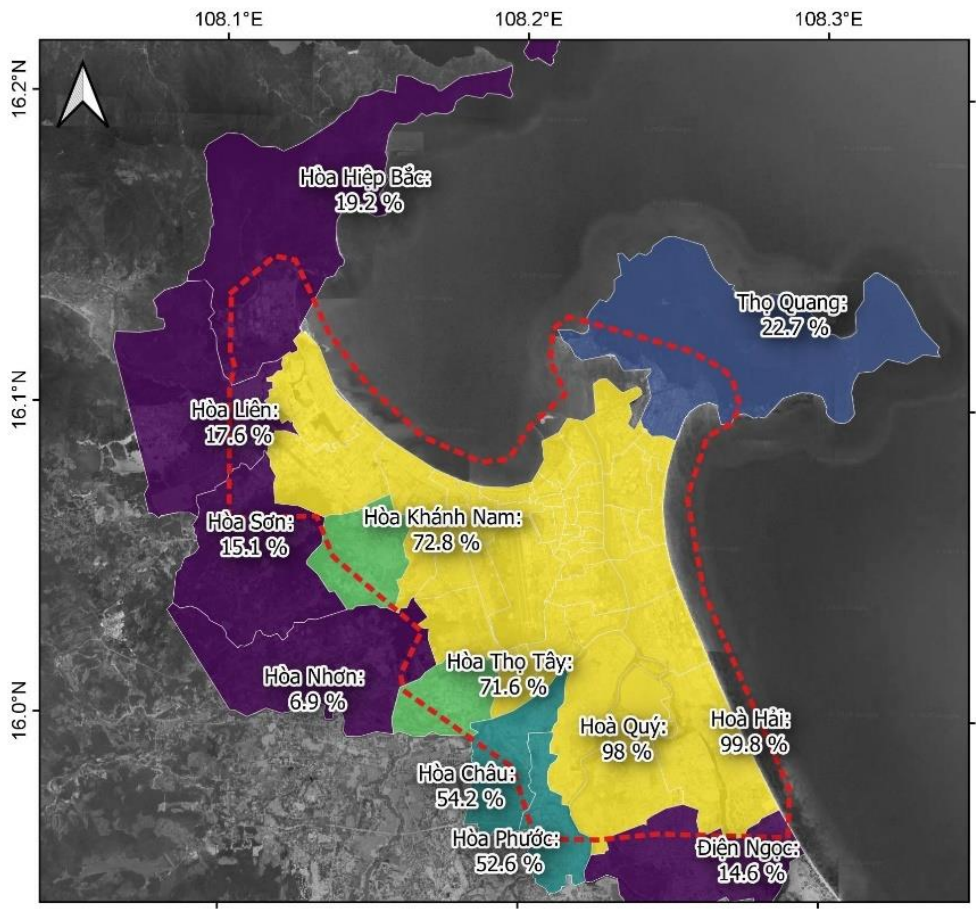

\section{Legend}

extent of the VHR satellite images
percent covered by satellite images
$7-20 \%$
$20-40 \%$
$40-60 \%$
$60-80 \%$
$80-100 \%$

Map projection: UTM 49N (EPSG:32649)

Data sources:

Administrative boundaries: (c) 2018

GADM, version 3.6

Satellite basemap: @ 2020 Digital Globe

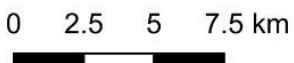

Figure A1. Share of each ward covered by the area of interest (AOI, extent of the satellite images) of this study. 


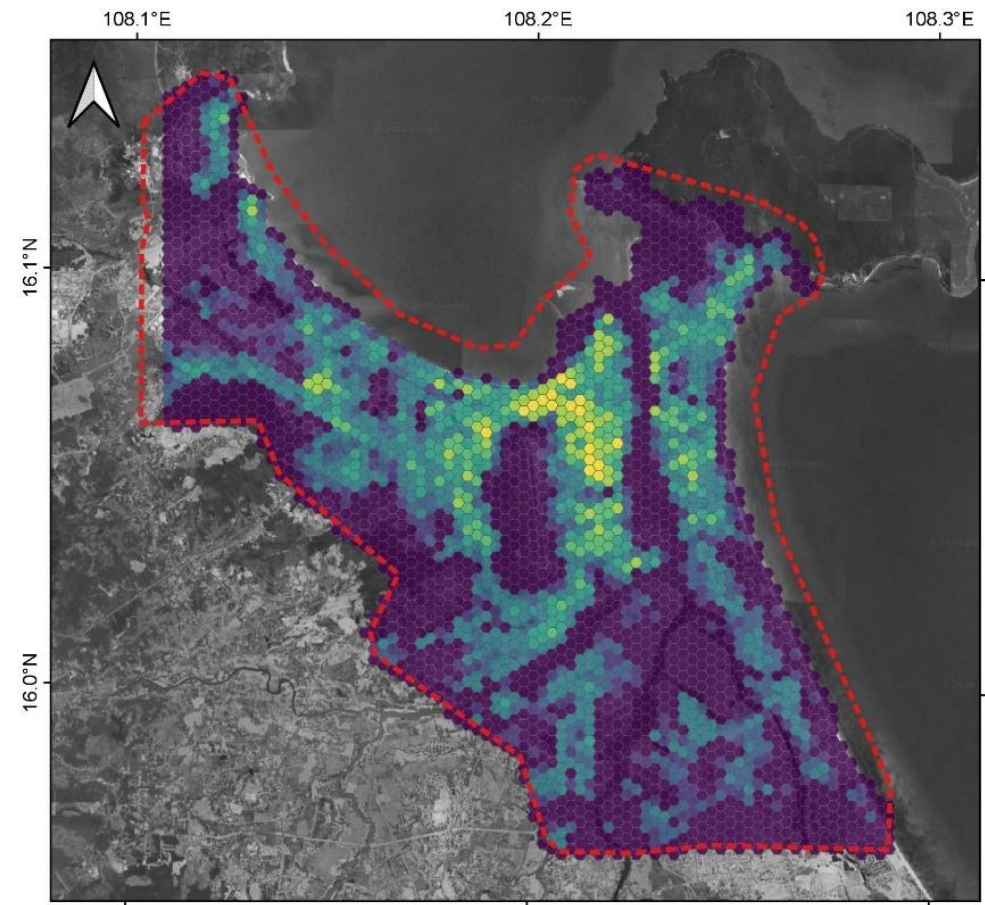

\section{Legend}

-. extent of the VHR satellite images

\section{buildings per hexagon}

$0-25$

$25-50$

$50-100$

$100-250$

$250-350$

$350-450$

$450-600$

$600-850$

Map projection: UTM 49N (EPSG:32649) Satellite basemap: @ 2020 Digital Globe

\section{$\begin{array}{llll}0 & 2.5 & 5 & 7.5 \mathrm{~km}\end{array}$}

Figure A2. Building density in 2017 aggregated by hexagons.
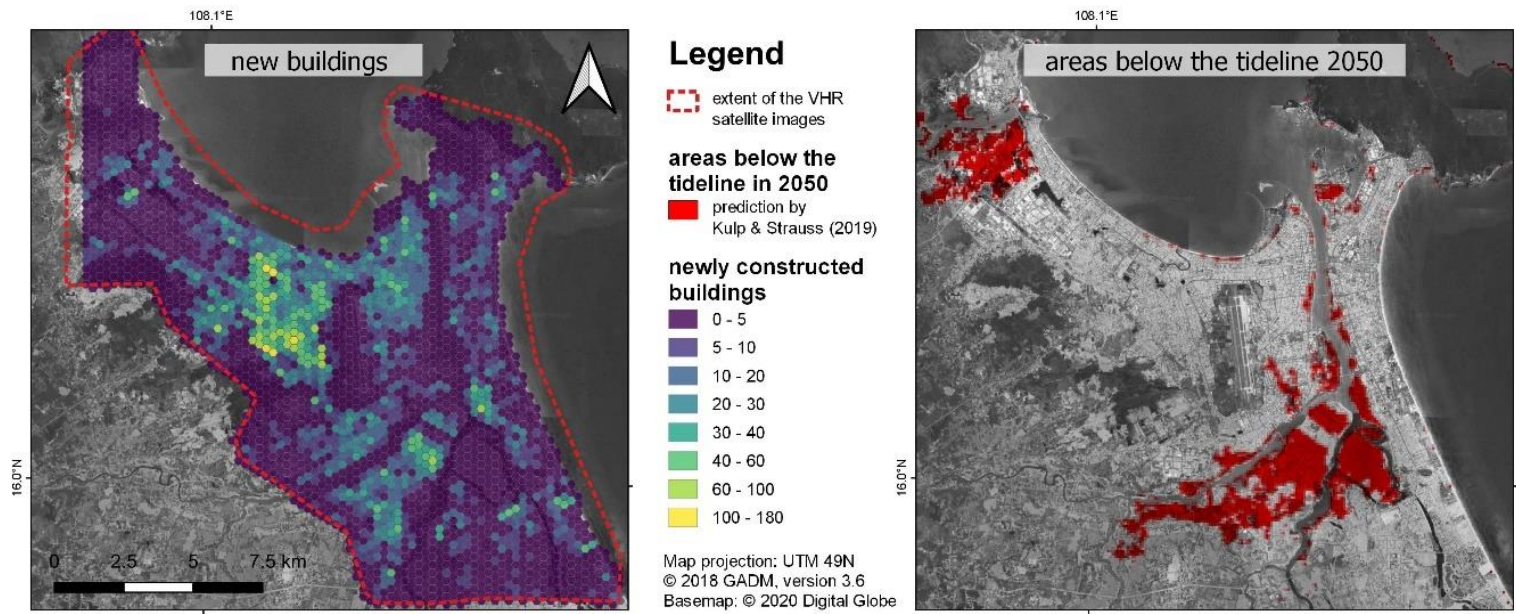

Figure A3. Absolute number of new buildings compared to areas expected to be below the tideline in 2050 by Kulp \& Strauss (2019) [19].

\section{References}

1. Zhang, B.-G. Application of remote sensing technology to population estimation. Chin. Geogr. Sci. 2003, 13, 267-271. [CrossRef]

2. Xie, Y.; Weng, A.; Weng, Q. Population estimation of urban residential communities using remotely sensed morphologic data. IEEE Geosci. Remote Sens. Lett. 2015, 12, 1111-1115.

3. Vetter-Gindele, J.; Braun, A.; Warth, G.; Bui, T.T.Q.; Bachofer, F.; Eltrop, L. Assessment of Household Solid Waste Generation and Composition by Building Type in Da Nang, Vietnam. Resources 2019, 8, 171. [CrossRef]

4. Warth, G.; Braun, A.; Bödinger, C.; Hochschild, V.; Bachofer, F. DSM-based identification of changes in highly dynamic urban agglomerations. Eur. J. Remote Sens. 2019, 52, 322-334. [CrossRef]

5. United Nations. World Population Prospects: Revision of 2019. Available online: https://population.un.org/ wpp/ (accessed on 23 February 2020). 
6. Ostojic, D.R.; Bose, R.K.; Krambeck, H.; Lim, J.; Zhang, Y. Energizing Green Cities in Southeast Asia; The World Bank: Washington, DC, USA, 2013; ISBN 978-0-8213-9837-1.

7. Burnett, M.G. Hexagon (KH-9). Mapping Camera Program and Evolution; United States Secretary of the Air Force: Washington, DC, USA, 2012.

8. Moon, K.; Downes, N.; Rujner, H.; Storch, H. Adaptation of the urban structure type approach for vulnerability assessment of climate change risks in Ho Chi Minh City. In Congress Report, Low Carbon Cities; International Planning Congress: Porto, Portugal, 2009.

9. Downes, N.K.; Storch, H.; Schmidt, M.; Nguyen, T.C.V.; Tran, T.N. Understanding Ho Chi Minh City's urban structures for urban land-use monitoring and risk-adapted land-use planning. In Sustainable Ho Chi Minh City: Climate Policies for Emerging Mega Cities; Katzschner, A., Waibel, M., Schwede, D., Katzschner, L., Schmidt, M., Storch, H., Eds.; Springer: Heidelberg, Germany, 2016; pp. 89-116. ISBN 978-3-319-04615-0.

10. Bachofer, F.; Braun, A.; Adamietz, F.; Murray, S.; d'Angelo, P.; Kyazze, E.; Mumuhire, A.P.; Bower, J. Building Stock and Building Typology of Kigali, Rwanda. Data 2019, 4, 105. [CrossRef]

11. GADM. Database of Global Administrative Areas: Version 3.6. Available online: https://gadm.org (accessed on 15 January 2020).

12. Birch, C.P.D.; Oom, S.P.; Beecham, J.A. Rectangular and hexagonal grids used for observation, experiment and simulation in ecology. Ecol. Model. 2007, 206, 347-359. [CrossRef]

13. Canny, J. A computational approach to edge detection. IEEE Trans. Pattern Anal. Mach. Intell. 1986, 679-698. [CrossRef]

14. Panagiotakis, E.; Chrysoulakis, N.; Charalampopoulou, V.; Poursanidis, D. Validation of Pleiades Tri-Stereo DSM in urban areas. ISPRS Int. J. Geo Inf. 2018, 7, 118. [CrossRef]

15. General Statistics Office of Vietnam. The 2009 Vietnam Population and Housing Census: Major Findings. Available online: https://www.gso.gov.vn/default_en.aspx?tabid=515\&idmid=5\&ItemID=9813 (accessed on 15 January 2020).

16. Hằng, N.H. Da Nang city development. In Knowledge Creation in Community Development; Nishihara, A.H., Matsunaga, M., Nonaka, I., Yokomichi, K., Eds.; Springer: Heidelberg, Germany, 2018; pp. 85-106.

17. Bachofer, F.; Rau, H. Change monitoring of a heterogeneous urban landscape using RapidEye data-DaNang, Vietnam. In Proceedings of the GIS 2015 Conference, Hue, Vietnam, 8-11 December 2016; pp. 702-707.

18. Linh, N.H.K.; Chuong, H.V. Assessing the impact of urbanization on urban climate by remote sensing perspective: A case study in DaNang city, Vietnam. Int. Arch. Photogramm. Remote Sens. Spat. Inf. Sci. 2015, XL-7/W3, 207-212. [CrossRef]

19. Kulp, S.A.; Strauss, B.H. New elevation data triple estimates of global vulnerability to sea-level rise and coastal flooding. Nat. Commun. 2019, 10, 4844. [CrossRef] [PubMed] 